\section{Viruses of Vertebrates}

Sir Christopher Andrews and H. G. Pereira. Second Edition. Pp. 432 + xiii. London: Baillére, Tindall \& Cassell, 1967. $£ 3$ 10s.

This second edition is as outstanding as the first in its interpretation of viruses of vertebrates. The first part is devoted to RNA and the second to DNA viruses, for this is the most fundamental present classification and also the most helpful for understanding future means of control. This classification also concerns itself with such basic criteria as the possession of cubical or helical symmetry in the arrangement of protein subunits. The presence of an outer envelope enclosing a more rigid structure is correlated with sensitivity to inactivation by ether, chloroform or desoxycholic acid. Since some viruses cannot yet be classified in this way, the third part of the book deals with unclassified viruses pathogenic for man, ungulates, other mammals, birds, fish and amphibia.

There is now general agreement that organisms of the psittacosis-lymphogranuloma-trachoma group, the Chalmydozoaceae, are bacteria related to the rickettsia, and not viruses. It is, therefore, illogical to retain them in this book. For the reader's convenience the names of the agents are listed together with the page-reference from the first edition of this book. Thus, libraries and individuals should retain their copies of the first edition while, at the same time, enriching themselves with this new version. It is hoped that the authors of the third edition will omit the recommendation on page 203 that killed measles virus vaccine should be followed later by attenuated virus, for unpleasant reactions are now recognized to follow such a regime. There is considerable re-awakening of interests in hepatitis but since it remains unclassified, it only rates a couple of pages, and likewise for serum hepatitis. This exemplifies the splendid discipline with which the authors have managed to contain themselves and a mass of information within 432 pages; symptomatology and lesions are dealt with more briefly than in most textbooks since this book is about viruses rather than virus diseases.

\section{Textbook of Gynaecology}

By John I. Brewer and Edwin J. De Costa. Fourth Edition. Pp. xxviii +918 , illustrated. Baltimore: Williams \& Wilkins, 1967. Price not given.

The first edition of this book was in 1953. In this fourth edition the material has been expanded and is now presented in three sections. The first section is medical gynaecology, topics such as induction and suppression of ovulation, abnormalities of sex and contraception have been discussed at chapter length for the first time. The third section is an account of the major gynaecological diseases. It is the intervening second section which distinguishes this Textbook of Gynaecology amongst others. It is a discussion of gynaecological symptoms and differential diagnoses. As the authors stress, this is the way practising clinicians must analyse their problems and organize their thinking. This teaching technique has been a feature of the book since its inception. It involves repetition and cross-reference to other sections where the diseases are described at length.

The book is written for medical students and junior doctors. The material is remarkably comprehensive and clearly presented with photographs. In the opinion of the reviewer this is a first class textbook and the consideration of symptoms and differential diagnoses is an invaluable section. The latest progress is presented in the new chapters in medical gynaecology. There is too much material for the average medical student but this ensures that the book remains of value in the years after qualification.

\section{Ovarian Physiology}

By George S. Richardson. Pp. 167, New England Journal of Medicine, Medical Progress Series. London: J. \& A. Churchill, 1967. 50s.

A monograph on Ovarian Physiology first appeared as a progress report in the New England Journal of Medicine. The book under review draws on this and incorporates additional material and illustrations. The 123-page book deals with the subject from four aspects. The first section is ovarian morphology, and a discussion of topics such as the origin of germ cells, the behaviour of follicles before puberty and the mechanism of ovulation, are of general interest. The second section is the physiology of the cycle: the interdependence of endocrine glands and genital organs is discussed. The remaining half of the book is devoted to steroidogenesis, except for a short section on pathology of the Stein-Levanthal syndrome and functioning ovarian tumours. There is an excellent list of $\mathbf{4 8 2}$ titled references.

A wealth of information is compacted in this short book. The interdisciplinary approach includes histological, pathological, physiological and biochemical data from a variety of species. The style is terse, the author assumes that many of the references are familiar to the reader. Inevitably much of the work has been in rodents and farm animals; a medical graduate is not familiar enough with these species to follow easily much of the work quoted.

One of the purposes of a monograph is to outline the foundations on which recent work is progressing. A summary of each section of the book would have helped the reader, be he primarily a pathologist, or biochemist or clinician, to digest the information from another discipline. Much of the data would have been clearer if presented in diagrammatic form (only seven figures are included). The author has written for 'the established investigator and for those who may wish to undertake investigation-and all who are drawn into the contemplation of feminine mysteries'. The book is recommended for these esoteric few. With a more lavish presentation, with diagrams and expanded explanation, it could have been suitable for a wider audience.

\section{Comprehensive Textbook of Psychiatry}

Edited by A. M. Freedman and H. I. Kaplan. Pp. xxv + 1666, illustrated. Baltimore: Williams \& Wilkins. Edinburgh and London: E. \& S. Livingstone, 1967. £9 18s.

In a preface which amounts to a carefully reasoned apologia, the editors of this weighty volume have set out a clear statement of their aims and intentions. 'Specifically', they write, 'it was decided (1) that the text should be multi-authored; (2) that the approach should be ecletic and multi-disciplinary, and (3) that the book should be comprehensive in scope...' The first of these aims, in their view, was simply a corollary of the last, since psychiatry has now advanced beyond the stage at which any one man can hope to assimilate all the important facts. Hence, they decided to seek the collaboration of a large number of experts, so as to produce a compilation along the lines of modern textbooks of medicine. In the event, material was contributed by nearly 200 specialists, many of whom are eminent in their chosen fields.

In addition to lengthy sections on what are termed the 'basic behavioral sciences' of neuro-anatomy, neuro-physiology, biochemistry, experimental psychology, sociology and anthropology, the book contains chapters on such topics as community, geriatric, forensic, military and industrial psychiatry, social work and psychiatric nursing. There is a 200-page exposition of child psychiatry with contributions by Kanner and Eisenberg, inter alia. A good deal of attention is devoted to various theoretical models, and to conflicting aetiological hypotheses. 